\title{
Prenatal exposure to lead and cognitive deficit in 7- and 14-year-old children in the presence of concomitant exposure to similar molar concentration of methylmercury
}

\section{Citation}

Yorifuji, Takashi, Frodi Debes, Pal Weihe, and Philippe Grandjean. 2011. “Prenatal Exposure to Lead and Cognitive Deficit in 7- and 14-Year-Old Children in the Presence of Concomitant Exposure to Similar Molar Concentration of Methylmercury." Neurotoxicology and Teratology 33 (2) (March): 205-211. doi:10.1016/j.ntt.2010.09.004. http://dx.doi.org/10.1016/j.ntt.2010.09.004.

\section{Published Version}

doi:10.1016/j.ntt.2010.09.004

\section{Permanent link}

http://nrs.harvard.edu/urn-3:HUL.InstRepos:34767901

\section{Terms of Use}

This article was downloaded from Harvard University's DASH repository, and is made available under the terms and conditions applicable to Other Posted Material, as set forth at http:// nrs.harvard.edu/urn-3:HUL.InstRepos:dash.current.terms-of-use\#LAA

\section{Share Your Story}

The Harvard community has made this article openly available.

Please share how this access benefits you. Submit a story. 


\title{
Prenatal Exposure to Lead and Cognitive Deficit in 7- and 14- Year-Old Children in the Presence of Concomitant Exposure to Similar Molar Concentration of Methylmercury
}

\author{
Takashi Yorifujia,b, Frodi Debes ${ }^{\mathrm{C}}$, Pal Weihe $^{\mathrm{C}}$, and Philippe Grandjean ${ }^{a, d}$ \\ aDepartment of Environmental Health, Harvard School of Public Health, Boston, MA 02215, USA \\ bDepartment of Epidemiology, Okayama University Graduate School of Medicine, Dentistry and \\ Pharmaceutical Sciences, Okayama 700-8558, Japan 'Department of Occupational Medicine and \\ Public Health, The Faroese Hospital System, FR-100 Tórshavn, Faroe Islands dDepartment of \\ Environmental Medicine, University of Southern Denmark, DK-5000, Odense, Denmark
}

\section{Abstract}

Few studies have examined the effects of mixed metal exposures in humans. We have evaluated the effect of prenatal lead exposure in a Faroese birth cohort in the presence of similar molar-level exposure to methylmercury. A cohort of 1022 singleton births was assembled in the Faroe Islands during 1986-1987 from whom lead was measured in cord blood. A total of 896 cohort subjects participated in a clinical examination at age 7 and 808 subjects in a second examination at age 14 . We evaluated the association between cord-blood lead concentrations and cognitive deficits (attention/working memory, language, visuospatial, and memory) using multiple regression models. Overall, the lead concentration showed no clear pattern of association. However, in subjects with a low methylmercury exposure, after inclusion of statistical interaction terms, leadassociated adverse effects on cognitive functions were observed. In particular, higher cord-blood lead was associated with a lower digit span forward score on the Wechsler Intelligence Scale for Children-Revised (WISC-R) [beta $=-1.70,95 \%$ confidence interval $(\mathrm{CI}):-3.12$ to -0.28 ] at age 7 and a lower digit span backward score on the WISC-R (beta $=-2.73,95 \% \mathrm{CI}:-4.32$ to -1.14 ) at age 14. Some interaction terms between lead and methylmercury suggested that the combined effect of the exposures was less than additive. The present study indicates that adverse effects of exposure may be overlooked if the effects of a co-pollutant are ignored. The present study supports the existence of adverse effects on cognitive functions at prenatal lead exposures corresponding to an average cord-blood concentration of $16 \mu \mathrm{g} / \mathrm{L}$.

(C) 2010 Elsevier Inc. All rights reserved

Address correspondence to: Takashi Yorifuji Department of Environmental Health, Harvard School of Public Health, 401 Park Drive, 3-112-12 East, Boston, MA 02215, USA Phone: 1-617-384-5404 Fax: 1-617-384-8994 tyorifuj@hsph.harvard.edu.

Publisher's Disclaimer: This is a PDF file of an unedited manuscript that has been accepted for publication. As a service to our customers we are providing this early version of the manuscript. The manuscript will undergo copyediting, typesetting, and review of the resulting proof before it is published in its final citable form. Please note that during the production process errors may be discovered which could affect the content, and all legal disclaimers that apply to the journal pertain.

Conflict of Interest Statement The authors declare that there are no conflicts of interest. In the interest of transparency, the author (PG) declares that he has provided paid expert testimony on mercury toxicology for the U.S. Department of Justice in a legal case concerning environmental pollution from coal-fired power plants. 


\section{Keywords}

Food contamination; Metal mixtures; Lead; Methylmercury Compounds; Neuropsychological tests; Prenatal exposure delayed effects

\section{Introduction}

The majority of environmental research on the effects of chemicals focus on single exposures. However, exposure to mixtures of chemicals is ubiquitous in real life [2]. Certain chemical substances may target the same organ and induce similar effects in an additive or non-additive way [5]. Recent studies suggest a synergistic effect of metal mixtures with neuropsychological outcomes [15,31] or kidney disease [19]. However, studies that examine the effects of chemical mixtures remain limited in humans, and even in experimental animal studies [5].

In the Faroe Islands, residents traditionally consume pilot whale meat [12], which contains high levels of methylmercury due to the whale feeding on other aquatic animals like squid. Thus, the Faroese residents are highly exposed to methylmercury. Hence from 1986 to 1987 approximately 1000 births were recruited as a birth cohort to evaluate the possible adverse effects of prenatal exposure to methylmercury [11]. Subsequent follow-up studies demonstrated the effects of the developmental exposure on neuropsychological outcomes $[6,12]$.

For the baseline study of the cohort, cord-blood lead was also measured. At this time, the molar lead concentration was similar in magnitude to the mercury concentration, but was not correlated with whale consumption or mercury [11]. The adverse effect of lead on neurodevelopment is conclusive [3], and recent studies consistently suggest that not only childhood exposure, but also prenatal exposure to lead is associated with intellectual deficit in childhood [13,14,16,17,23,27]. More recently, the European Food Safety Authority concluded that there is no evidence for a threshold for developmental lead neurotoxicity [7].

So far, studies which examined the possible adverse effects of methylmercury or lead only focused on a single exposure. Although a recent study has examined the effect of methylmercury on neurodevelopment among children exposed to lead at higher levels [4], none of the previous studies examined the effect of lead exposure in the presence of a similar molar concentration of methylmercury. Therefore, in the present study, we aim to evaluate the possible adverse effect of prenatal lead exposure on cognitive function in the presence of a co-pollutant (methylmercury) exposure in the Faroese birth cohort.

\section{Methods}

\subsection{Study design and subjects}

A cohort of 1022 singleton births was assembled in the Faroe Islands during a 21-month period in 1986-1987 to evaluate the possible adverse effects of prenatal exposure to methylmercury [12]. The study protocol was approved by the Ethical Review Committee for the Faroe Islands and the U.S. Institutional Review Boards, and written informed consent was obtained. At delivery, blood samples from the umbilical cord and hair samples of the mothers were collected for mercury analyses. Furthermore, the midwives collected information on the course of the pregnancy and the delivery, including nutritional habits and use of alcohol and tobacco during pregnancy. 
The cohort members were first invited at age 7 and then again at age 14 years for clinical examination to evaluate the association between prenatal methylmercury exposure and neurobehavioral outcomes [6,12]. At age 7, a total of 917 surviving children $(90.3 \%)$ completed the examination (Figure). Most of the children were examined at the National Hospital in Tórshavn, the capital of the Faroe Islands. The children underwent various neurophysiological and neuropsychological tests in addition to a physical examination. A parent (usually the mother) completed a self-administered questionnaire, which included questions about the child's past medical history and demographic characteristics.

Additionally, Raven's Progressive Matrices was used to evaluate and score the maternal cognitive function. At age 14, 878 of the 1010 surviving children (86.9\%) participated in the examination. The majority of the examinations were also conducted at the National Hospital in Tórshavn from 2000 to 2001. As with the subjects at age 7, the cohort members underwent various neurophysiological and neuropsychological examinations, and a selfadministered questionnaire was completed. At both 7 and 14 years of age, examinations were made available in Denmark to families who had moved there. To avoid information bias, the examiners were unaware of the subjects' exposure status.

In the present study, among the 917 subjects who had participated in examinations at age 7, we selected 909 subjects who had available cord-blood lead concentrations. As with the previous studies $[6,12]$, we excluded 13 subjects who had neurological disorders so that the final cohort of subjects for analyses of neuropsychological outcomes at age 7 was 896 . The median cord-blood lead concentrations among the initial cohort and the selected 896 subjects were exactly the same ( $17 \mu \mathrm{g} / \mathrm{L}$ or $82 \mathrm{nmol} / \mathrm{L})$ [11]. Thus, attrition would be unlikely to affect the association between lead exposure and cognitive function at age 7 . Of the 896 subjects selected for the first study at age 7 , a total of 808 subjects participated in the examination at age 14 .

\subsection{Measurement of Exposure}

We used the cord-blood lead concentration as a main exposure indicator [11]. Immediately after delivery, the midwife took a 10-ml blood sample from the umbilical cord with Abbott syringes equipped with Teflon-lined pistons (Abbott Ireland Ltd, Sligo, Ireland). The blood samples were kept frozen during transport and storage until analysis. Then, blood-lead levels were determined by electrothermal atomic absorption spectrometry. The equipment used was an atomic absorption spectrometer model 5000, equipped with Zeeman background correction, HgA-500 graphite furnace, and an AS-40 autosampler (Perkin-Elmer). The blood lead results were read in duplicate against a blood-based standard curve with standard reference material SRM 955 from the US National Institute of Standards and Technology (Gaithersburg, MD, USA) as primary standard. The total analytical imprecision was estimated to be $5.9 \%(n=85)$ and $1.8 \%(n=87)$ at blood lead levels of 0.25 and $1.63 \mu \mathrm{mol} / \mathrm{L}$, respectively. The accuracy of the lead determinations was ensured by using Seronorm Trace Element batch 901 and 902 (NycoMed) as quality control materials [11]. Lead concentrations were reported in $\mu \mathrm{g} / \mathrm{L}$ (for conversion to the traditional unit of $\mu \mathrm{g} / \mathrm{dL}$, divide by 10$)$.

As previously reported, mercury concentrations varied considerably in both cord blood and maternal hair; $15 \%$ of the cohort had hair-mercury concentration above $10 \mu \mathrm{g} / \mathrm{g}$, whereas only $4 \%$ were below $1 \mu \mathrm{g} / \mathrm{g}$ [11]. The value of $1 \mu \mathrm{g} / \mathrm{g}$ corresponds to the U.S. EPA reference dose for mercury exposure [26]. Molar concentrations in $\mathrm{nmol} / \mathrm{L}$ for both lead and mercury can be obtained by multiplying the result in $\mu \mathrm{g} / \mathrm{L}$ by 5 .

Polychlorinated biphenyls (PCBs) were measured in cord tissue only from a subset of cohort members and were not considered due to the weak neurotoxicity in this study [10], and 
because it was poorly associated with the lead concentration. The cord-blood PCB concentration is currently being measured.

\subsection{Measurement of Outcomes}

For the main outcomes, we selected neuropsychological tests which reflected relevant cognitive functions (attention/working memory, language, visuospatial, and memory) and were conducted both at ages 7 and $14[6,12]$. The tests selected were as follows: Wechsler Intelligence Scale for Children-Revised (WISC-R) digit span, WISC-R similarities, WISC-R block designs, Boston Naming Test, and California Verbal Learning Test - Children's version (CVLT-C).

Each of the five tests was described in detail in the previous 7-year examination report [12]. WISC-R digit span is a test of short-term memory and attention. Digit series of increasing length were presented until the child failed two series of the same length. Scores were calculated as the total number of correct forward trials in the examination at age 7, and the total number of trials of forward and backward, forward only, and backward only at the examination at age 14. The backward condition also fits the theoretical construct of working memory. WISC-R similarities is a test of verbal reasoning. This verbal task required the child to identify a common category linking two objects or ideas. WISC-R block design is considered to be a test of visuospatial reasoning. Children used red and white blocks to replicate $2 \times 2$ and $3 \times 3$ stimulus designs presented on cards. The Boston Naming Test is a test of picture naming vocabulary. Children were presented with line drawings of objects, which they then were asked to name. Scores were tabulated as the total number of corrects without or with semantic and phonemic cues. CVLT-C tests aspects of verbal learning and memory. A list of 12 shopping items was given over five learning trials at age 7. At age 14, a list of 15 items was given. Subjects were requested to repeat as many items as they could remember. The total score was the sum of the correct answers in all five trials. After recall of an interference list, recall of the initial list (short-delay recall) was requested. After 20 minutes of other tests, recall of the initial list was again requested (long-delay recall). Finally recognition of the items on the original list, presented among a greater number of false items, was requested (recognition).

\subsection{Statistical analyses}

Initially, logarithmic transformations of the cord-blood lead concentrations and its correlations with logarithmic transformed mercury concentrations in cord blood and maternal hair were calculated. Furthermore, the geometric means of cord-blood lead concentration in regard to obstetrical variables and demographic characteristics at ages 7 and 14 was also calculated.

In addition, we evaluated the effects of lead exposure on neuropsychological tests using multiple linear regression models. All of the scores were used as continuous variables. Although most of the outcomes approximated a Gaussian distribution, only WISC-R block design at age 7 was square-root transformed as in the previous study to approximate the distribution. In the models for neuropsychological outcomes at age 7, we adjusted for the same potential confounders as before [12], in addition to possible predictors of cord-blood lead and neuropsychological outcomes, i.e., smoking and alcohol drinking during pregnancy. The following variables were included in the multivariate models: age; sex; maternal Raven score; paternal employment (yes/no); paternal professional education (yes/ no); maternal professional education (yes/no); daycare at age 7 (yes/no); medical risk (yes/ no); maternal smoking during pregnancy (non-smoker; less than 10 cigarettes per day; more than 10 cigarettes per day; other types of tobacco); and maternal alcohol drinking during pregnancy (yes/no). Medical risk was defined as whether the children experienced medical 
conditions for neurological dysfunction i.e., low birth weight $(<2500 \mathrm{~g})$, and history of head trauma and meningitis. Age and maternal Raven score were treated as continuous variables.

In the models for neuropsychological outcomes at age 14, we also adjusted for potential confounders similar to those used in the previous study [6], as well as the adolescent's own smoking and alcohol drinking status. Thus, we selected the following variables: age; sex; maternal Raven score examined at the examination at age 7; paternal employment (yes/no); maternal employment (yes/no); subject's residence (villages in Faroes; towns in Faroes; Denmark) and the language spoken at home (Faroese; Danish); the current school grade $\left(6^{\text {th}}\right.$; $7^{\text {th. }} 8^{\text {th }}$ ); smoking status (non-smoker; smoker but not daily; daily smoker), and alcohol drinking status (yes/no). As in the earlier study, age and maternal Raven score were treated as continuous variables.

The logarithmic transformation of the cord-blood mercury concentration, which was a strong predictor of neuropsychological outcomes in this cohort, was also included in the adjustments. Furthermore, multiplicative terms were entered between cord-blood lead (continuous) and mercury (continuous) into the models to evaluate interaction.

Since methylmercury exposure was determined only with some degree of imprecision, and due to the well established methylmercury neurotoxicity [9], effects of confounding or imprecision may not be completely corrected for by adjusting for mercury exposure and interaction terms. Hence, to reduce residual methylmercury toxicity, subjects in a low-level exposure group were selected within the lowest quartile hair-mercury category $(\leq 2.61 \mu \mathrm{g} / \mathrm{g})$. Although the value is higher than the reference dose for mercury $(1 \mu \mathrm{g} / \mathrm{g})[26]$, we used the lowest quartile category to secure appropriate statistical power. Furthermore, we defined the low-exposure group by hair-mercury instead of cord-blood mercury as hair-mercury concentration has been used for risk assessment [29,30]. These multivariate analyses were then repeated including adjustment for cord-blood mercury. Additionally, multiplicative terms were entered between cord-blood lead (continuous) and mercury (continuous) into the models to evaluate interaction within the lowest quartile hair-mercury category.

All confidence intervals (CIs) were calculated at the 95\% level. PASW Statistics software (SPSS Japan Inc., version 18.0J) was used for the analyses.

\section{Results}

Geometric averages of cord-blood lead and cord-blood mercury were $15.7 \mu \mathrm{g} / \mathrm{L}$ ( $75.8 \mathrm{nmol} /$ $\mathrm{L})$ and $23.0 \mu \mathrm{g} / \mathrm{L}(114.7 \mathrm{nmol} / \mathrm{L})$, respectively. The cord-blood lead concentration was not associated with cord-blood mercury, nor with hair-mercury. The results for cord-blood lead, cord-blood mercury, and hair-mercury concentrations are summarized in Table 1.

Geometric averages for cord-blood lead concentration are separated by obstetrical variables and demographic characteristics at ages 7 and 14 in Table 2. Although the lead concentration did not differ between sex or tertile age category, tertile maternal Raven score had a negative association with cord-blood lead. As shown in the previous report of this cohort [11], smoking and alcohol drinking during pregnancy was associated with higher cord-blood lead concentration. Moreover, children who had a medical risk or attended childcare also had higher lead concentration. Regarding demographic characteristics at age 14, children who natively spoke Danish as a first language had higher cord-blood lead concentration at birth. Although 88 subjects were lost to follow-up at age 14, geometric averages of cord-blood lead were not different between subject who could be followed (15.1 $\mu \mathrm{g} / \mathrm{L})$ and subjects who could not be followed $(15.8 \mu \mathrm{g} / \mathrm{L})(\mathrm{p}=0.86)$. 
Table 3 shows the results of the adjusted betas and their p-values for the cord-blood lead concentration and neuropsychological tests at ages 7 and 14 among the total subjects. In the multivariate analyses, higher lead was associated with higher scores on Boston Naming Test and higher learning scores on CVLT-C at the examination at age 7. The results did not change substantially after we adjusted for cord-blood mercury. Even after we entered multiplicative terms between lead and mercury, all of the p-values of the interaction terms except digit span forward on WISC-R and long-term recall on CVLT-C at age 7 were large. Thus, we did not find evidence that mercury modified the effects of prenatal lead exposure on cognitive deficits among the total subjects. Although higher lead tended to be associated with lower scores on digit span at ages 7 and 14, the adjusted betas still showed conflicting results.

Table 4 displays the results of the adjusted betas and their p-values within the low mercury exposure category $(\mathrm{n}=222)$. Since the results did not change whether we adjusted or did not for cord mercury, we do not show the results without mercury adjustment. Although adverse effects of lead on digit span in WISC-R at ages 7 and 14 were detected, we did not observe a clear pattern of association.

Contrary to the results for all total subjects, the p-values of interaction terms were much smaller, i.e., mercury seemed to modify the effects of prenatal lead exposure within the lowest mercury exposure category. Notably p-values obtained from the analyses in digit span on WISC-R and some of the scores on CVLT-C at both ages were less than 0.10. Considering interaction terms in the models for these scores, higher cord-blood lead was associated with lower digit span forward scores on WISC-R (beta $=-1.70,95 \% \mathrm{CI}:-3.12$ to -0.28 ), lower learning scores on CVLT-C (beta $=-8.55,95 \% \mathrm{CI}:-16.75$ to -0.35 ), and lower recognition scores on CVLT-C (beta $=-1.61,95 \% \mathrm{CI}$ : -3.42 to 0.19 ) at age 7. Furthermore, higher cord-blood lead was associated with lower digit span backward scores on the WISC-R (beta $=-2.73,95 \% \mathrm{CI}:-4.32$ to -1.14 ) and lower learning scores on CVLT$\mathrm{C}$ (beta $=-7.48,95 \% \mathrm{CI}:-16.48$ to 1.52 ) at age 14. Although some of the p-values for the interaction were still large, almost all of the betas for lead exposure were negative and almost all of the betas for the interaction term were positive after entering multiplicative terms into the models, which meant lead and methylmercury effects were less than additive, i.e., a negative departure from additivity (i.e., subadditivity).

\section{Discussion}

This study examined the effects of prenatal lead exposure on cognitive deficits in the presence of a similar molar concentration of a neurotoxic co-pollutant (methylmercury) in 7and 14-year-olds born in the Faroe Islands. The analyses of the total cohort and those of cohort members without interaction terms among lower co-pollutant exposure category showed equivocal results. However, when the subjects were restricted to a lower copollutant category, and statistical interaction terms were entered within the category, adverse effects of prenatal lead exposure on cognitive functions in childhood were observed, especially on attention, learning and memory.

When the total cohort was considered (Table 3), lead exposure seemed to have beneficial effects on language (Boston Naming test) and learning (in CVLT-C) at age 7 despite adjustments for mercury. Furthermore, even when we entered multiplicative terms between mercury and lead, positive associations did not change and a positive association between lead and long-term recall in CVLT-C was observed. In contrast, a negative effect on digit span forward in WISC-R at age 7 was noted. These findings showed that, in the presence of the co-pollutant which varied considerably (and measured with a certain degree of imprecision), adjustment for it or entering an interaction term resulted in equivocal findings. 
Furthermore, since cognitive function is competitively impaired by methylmercury in the high mercury exposure category, the existence of lead exposure may not induce additional neurotoxic effects on cognitive function.

The present finding of a possible adverse effect of prenatal lead exposure on cognitive function (especially attention and memory) among the lowest mercury exposure category is consistent with previous studies [13,23,27]. Additionally, the present findings suggest adverse effects on cognitive functions at prenatal lead exposure corresponding to an average cord-blood concentration of $16 \mu \mathrm{g} / \mathrm{L}$, i.e., lower than the averages of previous studies of at least $62 \mu \mathrm{g} / \mathrm{L}$ cord blood $[13,23]$. Moreover, the persistence of the lead-associated effect on neuropsychological outcomes at age 14, is consistent with previous findings [21]. In the present study, we further observed positive interaction terms in the models for lower mercury exposure category. This finding suggests that, among the subjects with the least residual methylmercury toxicity, methylmercury modified the effects of prenatal lead exposure on cognitive deficits. Furthermore, it means that lead and methylmercury worked in subadditive way or in an antagonistic interaction, given that both have detrimental effects on cognitive function. This does not mean that one will cancel out the effect of the other, but rather that these neurotoxicants may compete to induce effects because only one complete sufficient cause is required for effects to occur [22].

Although several mechanisms of lead and methylmercury neurotoxicity are reported [28], one possible mechanism includes their dysregulation of neurochemicals [8]. Among these neurochemicals, glutamate and its ionotropic receptor [N-methyl-D-aspartate receptor (NMDAR)] are of particular interest. Indeed, several studies suggest that lead and methylmercury inhibit astrocytes from uptake of glutamate from synapses [18,24], which may lead to cell death. Furthermore, it is also reported that lead and methylmercury could alter NMDAR expression $[1,20,25]$. Since the NMDAR is considered to be related to important functions in neurodevelopment, especially in learning and memory [25], its alteration may result in lead- and methylmercury-induced cognitive deficits. If this mechanism plays an important role both in lead and methylmercury neurotoxicity, it may be reasonable to assume that an effect of lead exposure may be masked by the presence of high methylmercury exposure. Moreover, these two chemicals might not work in a synergistic way, but possibly in a competitive way due to parallel toxic mechanisms. The "less than additive" interaction effect between lead and methylmercury observed in the present study could be due to a threshold relationship on the NMDAR or possibly another receptor.

In the Faroe Islands, another co-pollutant, the PCBs, may affect human brain development due to maternal ingestion of contaminated pilot whale blubber. However, PCBs were only weakly associated with neuropsychological deficits [deficits on the Boston naming test (without cues, $\mathrm{p}=0.09$; with cues, $\mathrm{p}=0.03$ ) and long-term recall in CVLT-C $(\mathrm{p}=0.15)$ ], and not in the outcomes affected by lead in the present study [10]. Furthermore, as described, PCBs were not associated with lead exposure. Therefore, PCBs would be unlikely to cause confounding.

Furthermore, since cord-lead exposure was related to maternal smoking and alcohol drinking during pregnancy (Table 2), there is a possibility of residual confounding. However, in the present study, maternal alcohol and smoking during pregnancy was positively associated with the neuropsychological outcomes to which we found adverse lead effects. Hence, these possible residual confounding could not explain the present results.

In the present study, we could not evaluate the effect of postnatal exposure to lead on cognitive functions, thus we could not definitively examine which prenatal or postnatal 
exposures were more relevant to cognitive functions in childhood. Further studies are needed to confirm this.

The present study, which utilized a well-conducted birth cohort, suggests an important caveat in environmental health studies: we may overlook adverse effects or we may find spurious associations if we do not consider the existence of a co-pollutant. Furthermore, the present study supports the previous findings that prenatal lead exposure has an adverse effect on cognitive function, even when prenatal lead exposure corresponds to an average cord-blood concentration of $16 \mu \mathrm{g} / \mathrm{L}$.

\section{Acknowledgments}

This study was supported by grants from the US National Institute of Environmental Health Sciences (ES06112 and ES09797) and the Danish Medical Research Council. We would like to thank Katherine Herz for helping us to prepare the manuscript.

\section{References}

[1]. Basu N, Scheuhammer AM, Rouvinen-Watt K, Grochowina N, Evans RD, O'Brien M, Chan HM. Decreased N-methyl-D-aspartic acid (NMDA) receptor levels are associated with mercury exposure in wild and captive mink. Neurotoxicology. 2007; 28:587-93. [PubMed: 17267038]

[2]. Bellinger DC. Interpreting epidemiologic studies of developmental neurotoxicity: conceptual and analytic issues. Neurotoxicol Teratol. 2009; 31:267-74. [PubMed: 19595760]

[3]. Bellinger DC. Lead. Pediatrics. 2004; 113:1016-22. [PubMed: 15060194]

[4]. Cao Y, Chen A, Jones RL, Radcliffe J, Caldwell KL, Dietrich KN, Rogan WJ. Does background postnatal methyl mercury exposure in toddlers affect cognition and behavior? Neurotoxicology. 2010; 31:1-9. [PubMed: 19969021]

[5]. Carpenter DO, Arcaro K, Spink DC. Understanding the human health effects of chemical mixtures. Environ Health Perspect. 2002; 110(Suppl 1):25-42. [PubMed: 11834461]

[6]. Debes F, Budtz-Jorgensen E, Weihe P, White RF, Grandjean P. Impact of prenatal methylmercury exposure on neurobehavioral function at age 14 years. Neurotoxicol Teratol. 2006; 28:363-75. [PubMed: 16647838]

[7]. EFSA Panel on Contaminants in the Food Chain (CONTAM). Scientific Opinion on Lead in Food. EFSA Journal. 2010; 8:1570.

[8]. Fitsanakis VA, Aschner M. The importance of glutamate, glycine, and gamma-aminobutyric acid transport and regulation in manganese, mercury and lead neurotoxicity. Toxicol Appl Pharmacol. 2005; 204:343-54. [PubMed: 15845423]

[9]. Grandjean P, Landrigan PJ. Developmental neurotoxicity of industrial chemicals. Lancet. 2006; 368:2167-78. [PubMed: 17174709]

[10]. Grandjean P, Weihe P, Burse VW, Needham LL, Storr-Hansen E, Heinzow B, Debes F, Murata K, Simonsen H, Ellefsen P. Neurobehavioral deficits associated with PCB in 7-year-old children prenatally exposed to seafood neurotoxicants. Neurotoxicol Teratol. 2001; 23:305-17. and others. [PubMed: 11485834]

[11]. Grandjean P, Weihe P, Jorgensen PJ, Clarkson T, Cernichiari E, Videro T. Impact of maternal seafood diet on fetal exposure to mercury, selenium, and lead. Arch Environ Health. 1992; 47:185-95. [PubMed: 1596101]

[12]. Grandjean P, Weihe P, White RF, Debes F, Araki S, Yokoyama K, Murata K, Sorensen N, Dahl $\mathrm{R}$, Jorgensen PJ. Cognitive deficit in 7-year-old children with prenatal exposure to methylmercury. Neurotoxicol Teratol. 1997; 19:417-28. [PubMed: 9392777]

[13]. Hu H, Tellez-Rojo MM, Bellinger D, Smith D, Ettinger AS, Lamadrid-Figueroa H, Schwartz J, Schnaas L, Mercado-Garcia A, Hernandez-Avila M. Fetal lead exposure at each stage of pregnancy as a predictor of infant mental development. Environ Health Perspect. 2006; 114:1730-5. [PubMed: 17107860] 
[14]. Jusko TA, Henderson CR, Lanphear BP, Parsons PJ, Canfield RL. Blood lead concentrations < 10 microg/dL and child intelligence at 6 years of age. Environ Health Perspect. 2008; 116:243-8. [PubMed: 18288325]

[15]. Kim Y, Kim BN, Hong YC, Shin MS, Yoo HJ, Kim JW, Bhang SY, Cho SC. Co-exposure to environmental lead and manganese affects the intelligence of school-aged children. Neurotoxicology. 2009; 30:564-71. [PubMed: 19635390]

[16]. Lanphear BP, Dietrich K, Auinger P, Cox C. Cognitive deficits associated with blood lead concentrations < 10 microg/dL in US children and adolescents. Public Health Rep. 2000; 115:521-9. [PubMed: 11354334]

[17]. Lanphear BP, Hornung R, Khoury J, Yolton K, Baghurst P, Bellinger DC, Canfield RL, Dietrich KN, Bornschein R, Greene T. Low-level environmental lead exposure and children's intellectual function: an international pooled analysis. Environ Health Perspect. 2005; 113:894-9. and others. [PubMed: 16002379]

[18]. Nagaraja TN, Brookes N. Mercuric chloride uncouples glutamate uptake from the countertransport of hydroxyl equivalents. Am J Physiol. 1996; 271:C1487-93. [PubMed: 8944631]

[19]. Navas-Acien A, Tellez-Plaza M, Guallar E, Muntner P, Silbergeld E, Jaar B, Weaver V. Blood cadmium and lead and chronic kidney disease in US adults: a joint analysis. Am J Epidemiol. 2009; 170:1156-64. [PubMed: 19700501]

[20]. Ndountse LT, Chan HM. Methylmercury increases N-methyl-D-aspartate receptors on human SH-SY 5Y neuroblastoma cells leading to neurotoxicity. Toxicology. 2008; 249:251-5. [PubMed: 18597911]

[21]. Needleman HL, Schell A, Bellinger D, Leviton A, Allred EN. The long-term effects of exposure to low doses of lead in childhood. An 11-year follow-up report. N Engl J Med. 1990; 322:83-8. [PubMed: 2294437]

[22]. Rothman, KJ.; Greenland, S.; Lash, TL. Modern epidemiology. 3rd Edition. Wolters Kluwer Health/Lippincott Williams \& Wilkins; Philadelphia: 2008.

[23]. Schnaas L, Rothenberg SJ, Flores MF, Martinez S, Hernandez C, Osorio E, Velasco SR, Perroni E. Reduced intellectual development in children with prenatal lead exposure. Environ Health Perspect. 2006; 114:791-7. [PubMed: 16675439]

[24]. Struzynska L. The protective role of astroglia in the early period of experimental lead toxicity in the rat. Acta Neurobiol Exp (Wars). 2000; 60:167-73. [PubMed: 10909172]

[25]. Toscano CD, Guilarte TR. Lead neurotoxicity: from exposure to molecular effects. Brain Res Brain Res Rev. 2005; 49:529-54. [PubMed: 16269318]

[26]. U.S.EPA.. Mercury study report to Congress, Office of Air Quality Planning and Standards and Office of Research and Development. Washington, D.C.: U.S. Environmental Protection Agency; 1997.

[27]. Wasserman GA, Liu X, Popovac D, Factor-Litvak P, Kline J, Waternaux C, LoIacono N, Graziano JH. The Yugoslavia Prospective Lead Study: contributions of prenatal and postnatal lead exposure to early intelligence. Neurotoxicol Teratol. 2000; 22:811-8. [PubMed: 11120386]

[28]. Wigle, DT. Child health and the environment. Oxford University Press; New York, N.Y.: 2003.

[29]. World Health Organization. Environmental health criteria: 1. Mercury. Geneva: World Health Organization; 1976.

[30]. World Health Organization. Environmental health criteria: 101. Methylmercury. Geneva: World Health Organization; 1990.

[31]. Wright RO, Amarasiriwardena C, Woolf AD, Jim R, Bellinger DC. Neuropsychological correlates of hair arsenic, manganese, and cadmium levels in school-age children residing near a hazardous waste site. Neurotoxicology. 2006; 27:210-6. [PubMed: 16310252] 


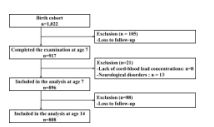

Figure.

Diagram showing number of eligible subjects and attrition. 
Table 1

Lead and mercury exposure parameters $(n=896)$

\begin{tabular}{lcccc}
\hline Exposure biomarker & $\mathbf{N}$ & Geometric average & Interquartile range & Correlations with cord blood lead $\boldsymbol{a}$ \\
\hline Cord blood lead $(\mu \mathrm{g} / \mathrm{l})$ & 896 & 15.7 & $12-22$ & 1 \\
Cord blood mercury $(\mu \mathrm{g} / \mathrm{l})$ & 873 & 23.0 & $13.6-42.1$ & 0.001 \\
Hair mercury $(\mu \mathrm{g} / \mathrm{g})$ & 893 & 4.3 & $2.6-7.8$ & 0.014 \\
\hline
\end{tabular}

${ }^{a}$ Correlations between log-transformed exposure biomarkers. 
Table 2

Geometric averages for the cord-blood lead concentration $(\mu \mathrm{g} / \mathrm{L})$, separated by obstetrical and demographic characteristics ( $\mathrm{n}=896$ at age 7 and 808 at age 14 years).

\begin{tabular}{|c|c|c|c|c|}
\hline & & $\mathbf{N}$ & Geometric average & p-value $c$ \\
\hline \multicolumn{5}{|c|}{ Obstetrical variables and demographic characteristics at 7 year } \\
\hline \multirow[t]{2}{*}{ Sex } & Boy & 447 & 15.7 & 0.64 \\
\hline & Girl & 449 & 15.8 & \\
\hline \multirow[t]{3}{*}{ Age (years) ${ }^{a}$} & $<6.7$ & 297 & 16.2 & 0.90 \\
\hline & $6.7-7.0$ & 298 & 15.5 & \\
\hline & $>7.0$ & 294 & 15.4 & \\
\hline \multirow[t]{3}{*}{ Maternal Raven score ${ }^{a}$} & $<43$ & 280 & 16.7 & 0.03 \\
\hline & $43-49$ & 302 & 15.3 & \\
\hline & $>49$ & 258 & 15.4 & \\
\hline \multirow[t]{2}{*}{ Paternal employment } & No & 145 & 16.3 & 0.80 \\
\hline & Yes & 740 & 15.6 & \\
\hline \multirow[t]{2}{*}{ Paternal professional education } & No & 260 & 11.0 & 0.28 \\
\hline & Yes & 625 & 9.1 & \\
\hline \multirow[t]{2}{*}{ Maternal professional education } & No & 471 & 15.5 & 0.88 \\
\hline & Yes & 413 & 15.9 & \\
\hline \multirow[t]{4}{*}{ Maternal smoking during pregnancy } & Non-smoker & 538 & 14.4 & 0.00 \\
\hline & Less than 10 cigarettes/d & 216 & 17.4 & \\
\hline & More than 10 cigarettes/d & 113 & 19.1 & \\
\hline & Other types of tobacco & 28 & 18.5 & \\
\hline \multirow[t]{2}{*}{ Maternal alcohol during pregnancy } & No & 679 & 15.3 & 0.00 \\
\hline & Yes & 216 & 17.1 & \\
\hline \multirow[t]{2}{*}{ Daycare } & No & 426 & 15.1 & 0.04 \\
\hline & Yes & 463 & 16.3 & \\
\hline \multirow[t]{2}{*}{ Medical risk $b$} & No & 764 & 15.6 & 0.02 \\
\hline & Yes & 125 & 16.3 & \\
\hline \multicolumn{5}{|l|}{ Demographic characteristics at 14 years } \\
\hline \multirow[t]{3}{*}{ Age (years) } & $<13.7$ & 273 & 16.3 & 0.77 \\
\hline & $13.7-14.0$ & 266 & 15.7 & \\
\hline & $>14.0$ & 269 & 15.3 & \\
\hline \multirow[t]{3}{*}{ Residence } & Villages in Faroes & 390 & 15.3 & 0.32 \\
\hline & Towns in Faroes & 336 & 16.1 & \\
\hline & Denmark & 81 & 17.2 & \\
\hline \multirow[t]{2}{*}{ Language used } & Faroese & 753 & 15.6 & 0.06 \\
\hline & Danish & 54 & 18.9 & \\
\hline \multirow[t]{2}{*}{ Paternal employment at 14 years old } & No & 50 & 16.4 & 0.66 \\
\hline & Yes & 741 & 15.7 & \\
\hline \multirow[t]{2}{*}{ Maternal employment at 14 years old } & No & 153 & 15.6 & 0.97 \\
\hline & Yes & 650 & 15.8 & \\
\hline
\end{tabular}




\begin{tabular}{lcccc}
\hline & & N & Geometric average & p-value \\
\hline Smoking at 14 years old & Non-smoker & 724 & 15.8 & 0.69 \\
& Smoker, but not daily & 26 & 16.5 & \\
\multirow{2}{*}{ Alcohol drinking at 14 years old } & Daily smoker & 44 & 17.0 & \\
& No & 760 & 15.8 & 0.72 \\
School grade & Yes & 34 & 17.2 & \\
& 6th & 55 & 15.5 & 0.49 \\
& 7 th & 708 & 15.8 & \\
\hline
\end{tabular}

${ }^{a}$ Age and Maternal Raven score were treated as tertile categories in this descriptive analysis.

${ }^{b}$ Medical risk was defined as to whether the children experienced medical conditions for neurological dysfunction (i.e., low birth weight and history of head trauma and meningitis).

${ }^{c}$ Chi-square tests of association for categories were conducted. 


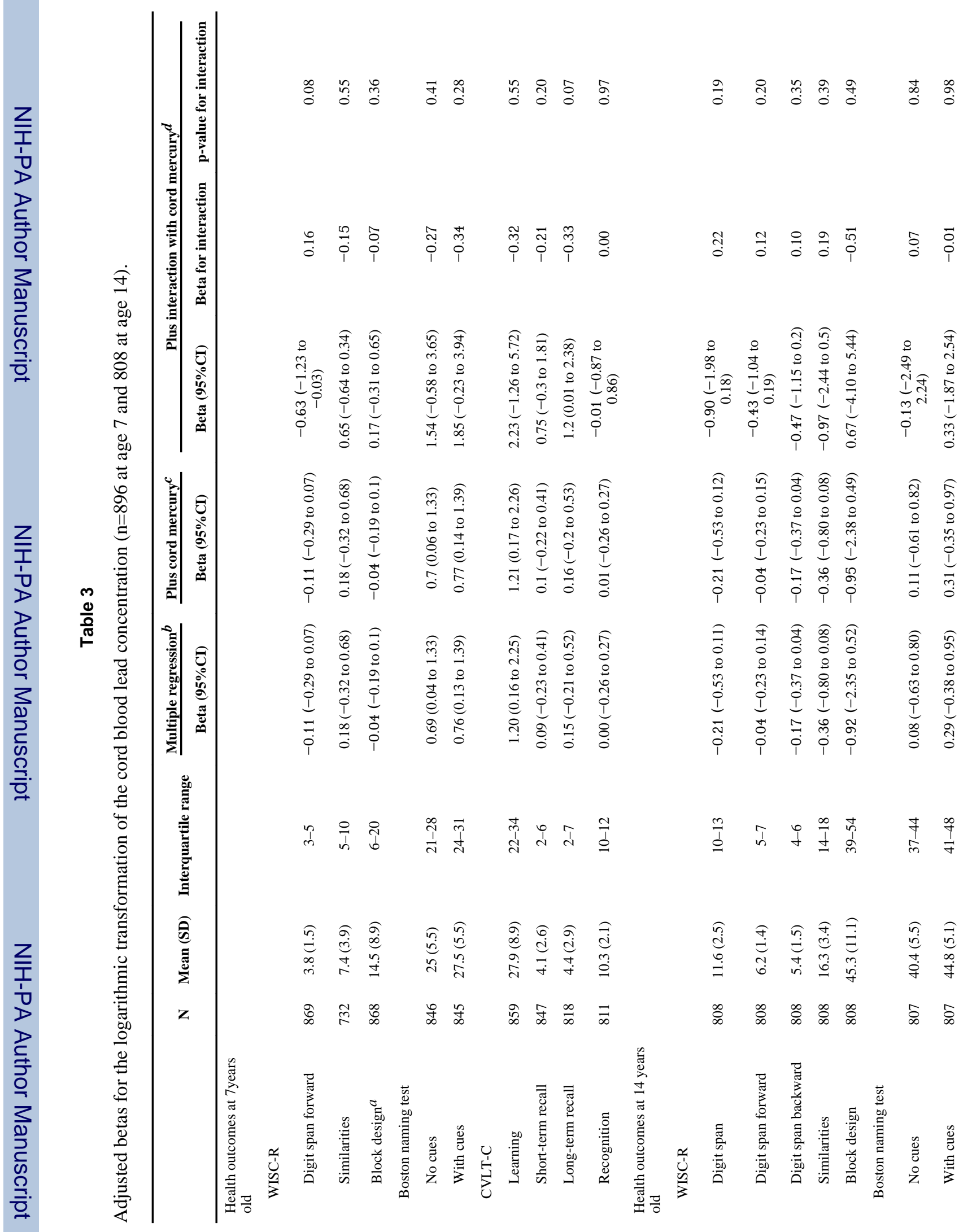


Yorifuji et al.

Page 15

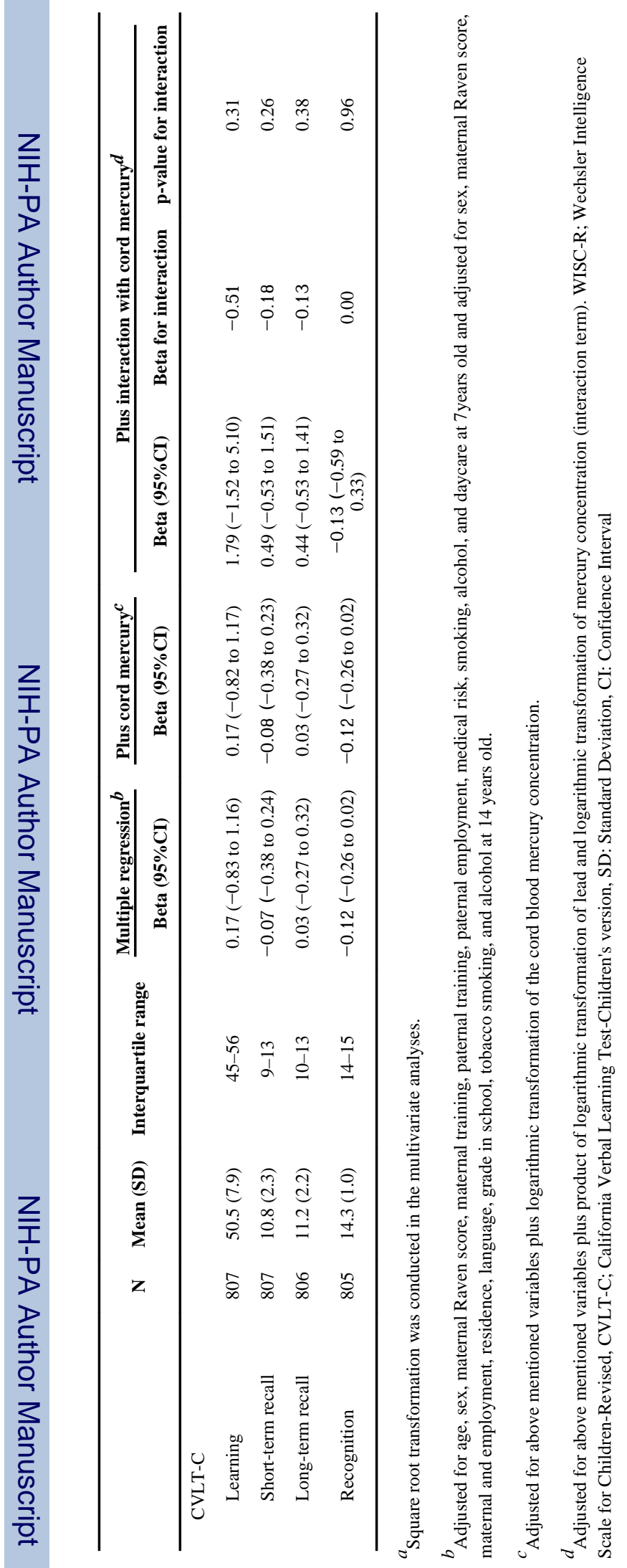

Neurotoxicol Teratol. Author manuscript; available in PMC 2012 March 1. 
Table 4

Adjusted betas for the logarithmic transformation of the cord blood lead concentration among the lowest quartile maternal hair mercury category $(\leq 2.61 \mu \mathrm{g} / \mathrm{g}, \mathrm{n}=222$ at age 7 and 199 at age 14).

\begin{tabular}{|c|c|c|c|c|}
\hline & \multirow{2}{*}{$\frac{\text { Full plus cord mercury }}{\text { Beta }(95 \% \mathrm{CI})}$} & \multicolumn{3}{|c|}{ Plus interaction with cord mercury $d$} \\
\hline & & Beta $(95 \% \mathrm{CI})$ & Beta for interaction & p-value for interaction \\
\hline \multicolumn{5}{|c|}{ Health outcomes at 7years old $b$} \\
\hline \multicolumn{5}{|l|}{ WISC-R } \\
\hline Digit span forward & $-0.47(-0.84$ to -0.09$)$ & $-1.70(-3.12$ to -0.28$)$ & 0.53 & 0.08 \\
\hline Similarities & $0.32(-0.87$ to 1.51$)$ & $-2.09(-6.49$ to 2.31$)$ & 1.05 & 0.26 \\
\hline Block design ${ }^{a}$ & $-0.06(-0.40$ to 0.27$)$ & $-0.18(-1.42$ to 1.05$)$ & 0.05 & 0.84 \\
\hline \multicolumn{5}{|l|}{ Boston naming test } \\
\hline No cues & $0.66(-0.85$ to 2.16$)$ & $-0.78(-6.42$ to 4.85$)$ & 0.62 & 0.60 \\
\hline With cues & $0.72(-0.76$ to 2.21$)$ & $-2.35(-8.00$ to 3.30$)$ & 1.32 & 0.27 \\
\hline \multicolumn{5}{|l|}{ CVLT-C } \\
\hline Learning & $1.24(-0.97$ to 3.44$)$ & $-8.55(-16.75$ to -0.35$)$ & 4.23 & 0.02 \\
\hline Short-term recall & $0.74(0.05$ to 1.43$)$ & $-1.16(-3.75$ to 1.43$)$ & 0.82 & 0.14 \\
\hline Long-term recall & $0.57(-0.23$ to 1.38$)$ & $0.63(-2.41$ to 3.68$)$ & -0.03 & 0.97 \\
\hline Recognition & $-0.05(-0.54$ to 0.44$)$ & $-1.61(-3.42$ to 0.19$)$ & 0.68 & 0.08 \\
\hline \multicolumn{5}{|c|}{ Health outcomes at 14 years old ${ }^{c}$} \\
\hline \multicolumn{5}{|l|}{ WISC-R } \\
\hline Digit span & $-1.00(-1.72$ to -0.29$)$ & $-4.56(-7.22$ to -1.89$)$ & 1.53 & 0.01 \\
\hline Digit span forward & $-0.41(-0.83$ to 0.00$)$ & $-1.83(-3.39$ to -0.27$)$ & 0.61 & 0.07 \\
\hline Digit span backward & $-0.59(-1.02$ to -0.16$)$ & $-2.73(-4.32$ to -1.14$)$ & 0.92 & 0.01 \\
\hline Similarities & $-0.12(-1.19$ to 0.94$)$ & $-2.51(-6.55$ to 1.52$)$ & 1.03 & 0.23 \\
\hline Block design & $-0.40(-4.06$ to 3.26$)$ & $4.12(-9.81$ to 18.06$)$ & -1.94 & 0.51 \\
\hline \multicolumn{5}{|l|}{ Boston naming test } \\
\hline No cues & $0.05(-1.64$ to 1.75$)$ & $-1.62(-8.08$ to 4.84$)$ & 0.72 & 0.60 \\
\hline With cues & $0.56(-0.96$ to 2.08$)$ & $0.04(-5.76$ to 5.83$)$ & 0.23 & 0.85 \\
\hline \multicolumn{5}{|l|}{ CVLT-C } \\
\hline Learning & $0.63(-1.76$ to 3.02$)$ & -7.48 ( -16.48 to 1.52$)$ & 3.48 & 0.07 \\
\hline Short-term recall & $0.23(-0.52$ to 0.99$)$ & $-0.15(-3.04$ to 2.74$)$ & 0.17 & 0.79 \\
\hline Long-term recall & $0.70(0.00$ to 1.41$)$ & $-1.70(-4.37$ to 0.96$)$ & 1.03 & 0.07 \\
\hline Recognition & $-0.01(-0.38$ to 0.36$)$ & $-0.90(-2.33$ to 0.53$)$ & 0.38 & 0.20 \\
\hline
\end{tabular}

${ }^{a}$ Square root transformation was conducted in the multivariate analyses.

${ }^{b}$ Adjusted for age, sex, maternal Raven score, maternal training, paternal training, paternal employment, medical risk, smoking, alcohol, daycare, and logarithmic transformation of the cord blood mercury concentration.

${ }^{c}$ Adjusted for sex, maternal Raven score, maternal and employment, residence, language, grade in school, tobacco smoking, alcohol, and logarithmic transformation of the cord blood mercury concentration.

${ }^{d}$ Adjusted for above mentioned variables plus product of logarithmic transformation of lead and logarithmic transformation of mercury concentration (interaction term). WISC-R; Wechsler Intelligence Scale for Children-Revised, CVLT; California Verbal Learning Test-Children's version, CI: Confidence Interval 